\title{
Reversal of Pipecuronium-Induced Moderate Neuromuscular Block with Sugammadex in the Presence of a Sevoflurane Anesthetic: A Randomized Trial
}

\author{
Edömér Tassonyi, MD, PhD, DSc,* Adrienn Pongrácz, MD,* Réka Nemes, MD,* László Asztalos, MD,* \\ Szabolcs Lengyel, PhD, DSc,† and Béla Fülesdi, MD, PhD, Dsc*
}

\begin{abstract}
BACKGROUND: Pipecuronium is a steroidal neuromuscular blocking agent. Sugammadex, a relaxant binding $\gamma$-cyclodextrin derivative, reverses the effect of rocuronium, vecuronium, and pancuronium. We investigated whether sugammadex reverses moderate pipecuronium-induced neuromuscular blockade (NMB) and the doses required to achieve reversal.

METHODS: This single-center, randomized, double-blind, 5-group parallel-arm study comprised 50 patients undergoing general anesthesia with propofol, sevoflurane, fentanyl, and pipecuronium. Neuromuscular monitoring was performed with acceleromyography (TOF-Watch SX ${ }^{\circledR}$ ) according to international standards. When the NMB recovered spontaneously to train-of-four count 2, patients randomly received $1.0,2.0,3.0$, or $4.0 \mathrm{mg} / \mathrm{kg}$ of sugammadex or placebo. Recovery time from sugammadex injection to normalized train-of-four (TOF) ratio 0.9 was the primary outcome variable. The recovery time from the sugammadex injection to final T1 was the secondary end point. Postoperative neuromuscular functions were also assessed.

RESULTS: Each patient who received sugammadex recovered to a normalized TOF ratio of 0.9 within 5.0 minutes (95\% lower confidence interval for the lowest dose $70.1 \%$; for all doses $90.8 \%$ ) and $79 \%$ of these patients reached a normalized TOF ratio 0.9 within 2.0 minutes $(95 \%$ lower confidence interval for the lowest dose $26.7 \%$; for all doses $63.7 \%$ ). T1 recovered several minutes after the TOF ratio. No residual postoperative NMB was observed.

CONCLUSIONS: Sugammadex adequately and rapidly reverses pipecuronium-induced moderate NMB during sevoflurane anesthesia. Once the train-of-four count has spontaneously returned to 2 responses following pipecuronium administration, a dose of $2.0 \mathrm{mg} / \mathrm{kg}$ of sugammadex is sufficient to reverse the NMB. (Anesth Analg 2015;XXX:00-00)
\end{abstract}

P ipecuronium bromide is a long-acting nondepolarizing steroidal neuromuscular blocking agent (NMBA), and a bisquaternary ammonium compound similar to pancuronium bromide. ${ }^{1,2}$ Pipecuronium was introduced in clinical practice in the late 1970s. ${ }^{3}$ Unlike pancuronium, pipecuronium has few if any cardiovascular side-effects ${ }^{4}$ and histamine release does not appear to be a problem. ${ }^{5}$ The average effective dose of the neuromuscular agent producing a $95 \%$ reduction in twitch height $\left(E D_{95}\right)$ for pipecuronium is approximately $0.045 \mathrm{mg} / \mathrm{kg}(0.035-0.059 \mathrm{mg} / \mathrm{kg}){ }^{6,7}$ The onset of action (mean time from start of injection to $90 \%$ twitch suppression or to maximum block) varies from 2.0 minutes $\left(2 \times \mathrm{ED}_{95}\right)$ to 6.3 minutes $\left(1 \times \mathrm{ED}_{95}\right)^{8-10}$ and the clinical duration (mean time to $25 \%$ recovery of the twitch height) varies from 29 minutes $\left(1 \times \mathrm{ED}_{95}\right)$ to 110 minutes $\left(2 \times \mathrm{ED}_{95}\right)$, as it is influenced by the dose and the anesthetic technique used. ${ }^{8-10}$

Pipecuronium undergoes very little metabolism and is excreted by the kidney and the liver. ${ }^{11}$ Owing to its relatively long duration of action and to the residual postoperative

From the *Department of Anesthesiology and Intensive Care, University of Debrecen, Debrecen, Hungary; and +Department of Ecology, Hungarian Academy of Sciences, Centre for Ecological Research, Debrecen, Hungary.

Accepted for publication January 29, 2015

Funding: The present work was supported from departmental funds only, no external sources were received.

The authors declare no conflicts of interest

Reprints will not be available from the authors.

Address correspondence to Béla Fülesdi, MD, PhD, Dsc, Department of Anesthesiology and Intensive Care, University of Debrecen, Nagyerdei krt. 98, Debrecen H_4032, Hungary. Address e-mail to fulesdi@med.unideb.hu.

Copyright ( 2015 International Anesthesia Research Society DOI: 10.1213 /ANE.0000000000000766 neuromuscular block (RPONB), the use of pipecuronium was discontinued in the United States and in several European countries. Because of its excellent safety profile, the use of pipecuronium has been maintained in several countries including China, Russia, Brazil, and Hungary, among others. Its safe use, however, is dependent on the availability of a reliable reversal drug. Although widely used, there are concerns with the use of neostigmine for reversal. These include undesirable muscarinergic side effects, limited ability to antagonize profound neuromuscular block (NMB), ${ }^{12}$ or prolonged time to full recovery, even when administered with 4 palpable responses to train-offour (TOF) stimulation. ${ }^{13,14}$ Because of these limitations with neostigmine, investigators continue to seek alternatives for reversal of NMB. ${ }^{15}$ Sugammadex, a modified $\gamma$-cyclodextrin compound, has emerged as a new reversal drug, and acts as a specific encapsulator of steroidal relaxants. ${ }^{14}$ Sugammadex readily reverses the effect of rocuronium or vecuronium by encapsulating the relaxant molecules in the plasma, lowering the concentration of free drug. The NMBA then diffuses away from prejunctional and postjunctional nicotinic acetylcholine receptors based on concentration gradients. ${ }^{14,16}$

The encapsulation of steroidal relaxants by sugammadex is a one-to-one molecular interaction depending on the affinity of sugammadex for these substances. Sugammadex has a high affinity for pipecuronium. As pipecuronium is about 6 to 7 times more potent than rocuronium, ,,17 fewer molecules are required to achieve a comparative blockade than in the case of rocuronium. The ability of sugammadex to reverse pipecuronium-induced NMB in anesthetized patients remains unknown. Furthermore, no study 
has investigated the appropriate dose of sugammadex to reverse NMB from pipecuronium.

The aim of this study was to establish the dose of sugammadex required to reverse a moderate (train-of-four count 2 [TOFC-2]) pipecuronium-induced NMB in surgical patients. We also investigated whether reversing the NMB from pipecuronium with sugammadex influences the occurrence of RPONB or recurrent NMB. We hypothesized that the dose of sugammadex recommended for the reversal of rocuronium-induced block $(1.0-4.0 \mathrm{mg} / \mathrm{kg})$ would also reverse the effect of pipecuronium. We also hypothesized that sugammadex reversal of pipecuronium NMB would result in minimal RPONB or recurrent NMB.

\section{METHODS}

\section{Trial Design and Participants}

This single-center, randomized, double-blind, 5-group parallel-arm study was approved by the local ethics committee at the University of Debrecen, Hungary (DEOEC RKEB/IKEB 3585-2012) and by the National Institute of Pharmaceutics (Országos Gyógyszerészeti Intézet, Budapest, Hungary). The study is classified under EUDRACT number 2012-000 29-14.

The investigations and data collection were performed at the University Hospital of Debrecen, Hungary, between 2012 August and 2014 January. Data reporting follow the CONSORT 2010 recommendations. ${ }^{a}$

Fifty participants were recruited from patients scheduled for routine elective surgery and gave written, informed consent to participate. Subjects were randomly assigned to 1 of the 5 study groups to receive $1.0,2.0,3.0$, and $4.0 \mathrm{mg} / \mathrm{kg}$ of sugammadex or $0.9 \%$ saline (Fig. 1). Eligibility criteria were age of 18 to 65 years, body mass index 18.5 to $25.0 \mathrm{~kg} / \mathrm{m}^{2}$, ASA physical status I to III, and scheduled for elective surgery with an expected duration of 90 minutes or more of general anesthesia that required tracheal intubation. Exclusion criteria were suspected difficult airway, bronchial asthma, chronic obstructive pulmonary disease, neuromuscular disease, suspected malignant hyperthermia, significant hepatic or renal dysfunction, glaucoma, allergy to drugs used in this trial, and taking medication known to influence the effect of NMBAs. Additional exlusions included patients who had participated in another study within the past month, or pregnant or breastfeeding patients.

\section{Interventions and Neuromuscular Monitoring}

Patients received $7.5 \mathrm{mg}$ of midazolam orally 1 hour before induction of anesthesia. In the operating room, an IV cannula was inserted in a forearm vein. Noninvasive blood pressure, electrocardiogram, and oxygen saturation measurements were started. Induction of anesthesia consisted of IV propofol $(1.5-2.0 \mathrm{mg} / \mathrm{kg})$ and fentanyl $(2.0 \mu \mathrm{g} / \mathrm{kg})$. Maintenance of anesthesia consisted of inhaled sevoflurane (1.0-1.3 average vol\%) in air-oxygen mixture and IV fentanyl according to clinical need. Patients' lungs were manually ventilated using a facemask until intubation of the trachea. Oxygen saturation was maintained above $96 \%$, normocapnia was ensured, and body temperature was maintained at $36^{\circ} \mathrm{C}$ or higher using forced air warming system (Bair-Hugger ${ }^{\circledR}$ Arizant Healthcare Inc., Eden Prairie, MN).

${ }^{a}$ Available at: www.consort-statement.org.
The TOF-Watch-SX ${ }^{\circledR}$ acceleromyograph (Organon Teknika B.V., Boxtel, Holland) was used for monitoring adductor pollicis muscle contractions in response to ulnar nerve stimulation. The piezoelectric probe of the acceleromyograph was attached to the tip of the thumb. A hand adapter ensured preload of the thumb while ensuring that it continued to return to its exact original position. ${ }^{18}$ The forearm and the fingers were immobilized, and surface skin electrodes were placed over the ulnar nerve proximal to the wrist. A TOF mode of stimulation was started and repeated every 15 seconds for 3 minutes followed by a 5-second tetanic train of $50 \mathrm{~Hz}$. Two minutes later, automatic calibration was performed (CAL-2 to set out supramaximal current intensity and calibration of the device). TOF stimulation was recommenced (supramaximal square wave stimuli of 0.2 millisecond duration at $2 \mathrm{~Hz}$ frequency) until the signal was stable. If the signal was not stable, the calibration was repeated. Data were recorded and stored on a computer using TOF-Watch SX software version 2.2 INT (Organon Ireland Ltd. Dublin, Ireland). Skin temperature was measured at the forearm near to the wrist and maintained above $32^{\circ} \mathrm{C}$. Once the neuromuscular recording was stable, $0.06 \mathrm{mg} / \mathrm{kg}$ (about $1.3 \times \mathrm{ED}_{95}$ ) pipecuronium was injected IV, and the trachea was intubated when the muscle response to TOF stimulation disappeared. During surgery, $0.01 \mathrm{mg} / \mathrm{kg}$ of pipecuronium was given at TOF count 1 to maintain muscle relaxation as needed. The TOF stimulation was automatically repeated every 15 -second interval during the procedure. At the end of surgery, patients were allowed to spontaneously recover from the NMB. Once the TOF-Watch SX monitor displayed 2 responses to TOF stimulation, a member of the investigative team (the anesthesiologist, who had prepared the study drug), injected it upon the request of the anesthesiologist who was responsible for the patient. The anesthesiologists caring for the patient remained blinded to the drug. The TOF ratio (T4/T1) and T1 amplitude (the first of 4 twitches to TOF stimulation) were recorded and analyzed later. Once the displayed TOF ratio was 1.0, sevoflurane was discontinued. The trachea was extubated when the patient emerged from anesthesia.

For incomplete recovery (stagnation of TOF ratio at $<0.9$ for at least 5 minutes), during the first 45 minutes following emergence from anesthesia, rescue reversal of NMB consisted of $0.015 \mathrm{mg} / \mathrm{kg}$ atropine and $0.05 \mathrm{mg} / \mathrm{kg}$ neostigmine.

\section{Postoperative Assessment}

After extubation of the trachea, patients were transferred to the recovery room. The stimulator was set on standby mode during the transport and the forearm and the hand adapter's positioning were secured. In the recovery room, a separate anesthesiologist, blinded to the study drug, performed acceleromyographic and clinical assessments of the neuromuscular function.

Postoperative acceleromyographic recordings were commenced (time zero) without recalibration of the device and were repeated every 20 minutes until 60 minutes. At each point in time, 3 consecutive TOF stimuli were delivered at 15 -second interval and the averages of 3 evoked TOF ratios were considered. Data were recorded and stored on a computer, and analyzed offline. TOF ratios less than 0.9 were defined as RPONB. 


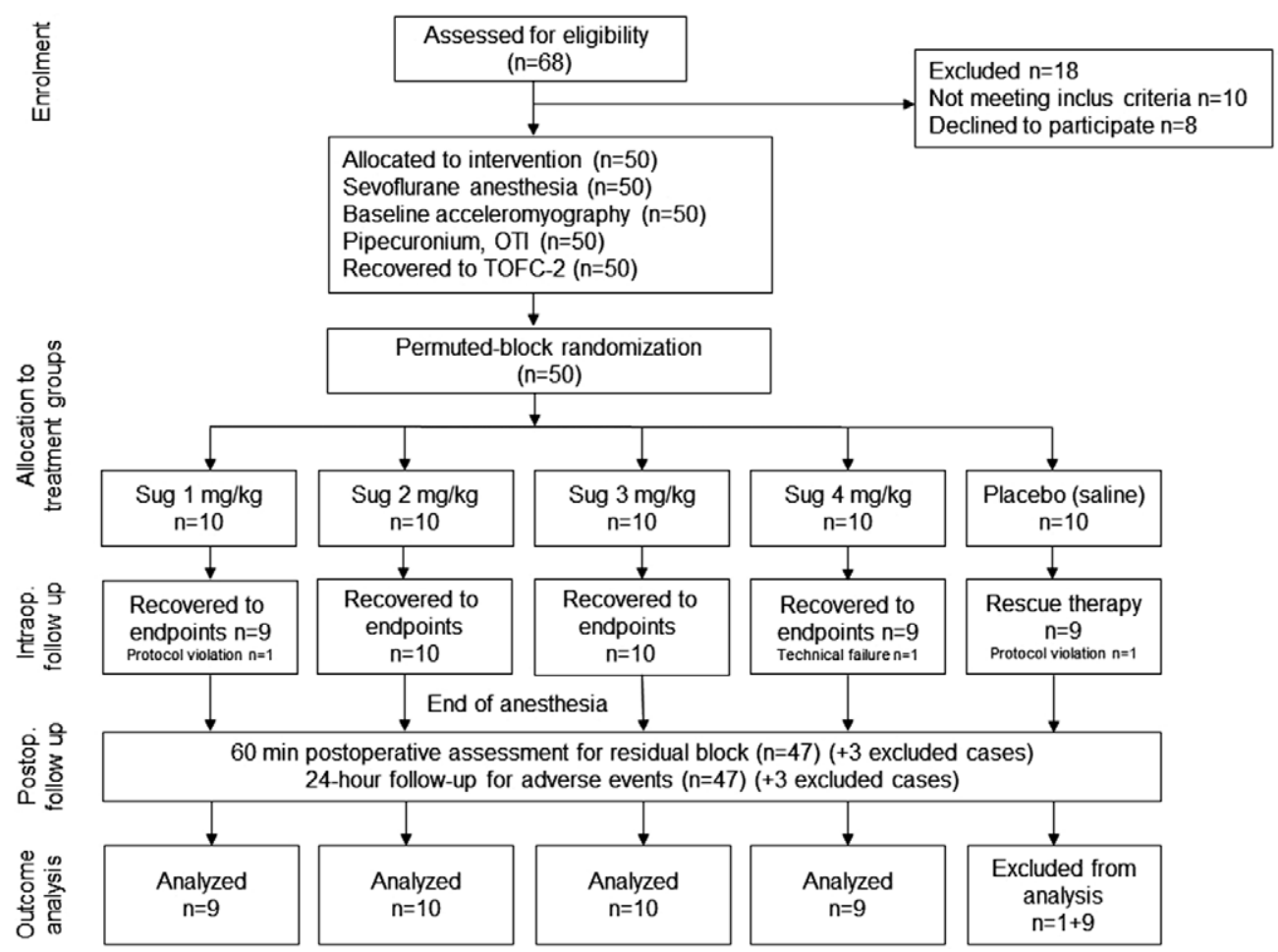

Figure 1. Study flowchart. The administration of sugammadex (Sug) and placebo was randomized and double blinded. The administration of pipecuronium was open. OTI = orotracheal intubation; TOFC- 2 = spontaneous recovery to 2 twitches. End-points were normalized train-of-four (TOF) 0.9 , nonnormalized TOF $\geq 1.0$, and maximal T1. Rescue therapy was neostigmine.

Oxygen saturation, noninvasive blood pressure, electrocardiogram, and respiratory rate were monitored. In responsive patients, head lift, arm-leg raise, hand grip, eye opening, smiling, tongue protrusion, coughing, double vision, and self-assessment of strength were evaluated every 20 minutes. ${ }^{19}$

Any sign of muscle weakness and critical respiratory or circulatory events were noted. After discharge from the recovery room, as a safety measure, patients were observed for 24 hours to detect late adverse events.

\section{Outcome Measures}

TOF ratio and the T1 height were assessed as efficacy variables. Normalized values of these parameters were calculated by dividing the recorded values at recovery by the baseline values before administration of pipecuronium.

The primary outcome measure was the time from the start of injection of the study drug to normalized TOF ratio of 0.9 . The secondary outcome measure was the time from the start of injection of the study drug to final $\mathrm{T} 1$ (the first of maximal $\mathrm{T} 1$ values at stable signal).

An alternative outcome measure was the time necessary to achieve nonnormalized TOF ratio of $\geq 1.0$ (the first of 3 consecutive responses).

The postoperative outcome measure was RPONB defined as nonnormalized TOF ratio less than 0.9 , with or without muscle weakness or critical respiratory events.

\section{Sample Size}

We assumed the spontaneous recovery time from a $0.06 \mathrm{mg} / \mathrm{kg}$ pipecuronium-induced block would be $60 \pm 30$ minutes (mean $\pm \mathrm{SD})^{20}$ and a reduction of the recovery time by 10 minutes with the lowest dose $(1.0 \mathrm{mg} / \mathrm{kg})$ of sugammadex. Using a Type 1 error rate $(\alpha)$ of 0.05 , a sample size $(n)$ of 6 in the treatment groups would be needed to reach a power of 0.8 and $n$ of 8 would result in a power of 0.9 . We included 10 patients in each group to allow for dropouts.

\section{Randomization and Blinding}

Subjects were randomly allocated to 5 study groups to receive $1.0,2.0,3.0$, and $4.0 \mathrm{mg} / \mathrm{kg}$ of sugammadex or placebo. Permuted-block randomization was used to ensure equal numbers of subjects per group. ${ }^{21}$ A sealed envelope method was used to assign participants to study groups. A designated anesthesiologist prepared the study drug and administered it in the operating room, while the patients and the anesthesiologists attending to the patient perioperatively remained blinded to the group to which the patients had been assigned.

\section{Statistical Methods}

The Fisher exact test was used to compare proportions across categories of $2 \times 2$ contingency tables. Ninety-five percent confidence intervals (CIs) around single proportions were estimated using the Wilson score method, or when $100 \%$ of events were observed, the Clopper-Pearson method. For continuous variables, parametric statistical tests were used if their assumptions were met by the data. The Bartlett test was used to check the homogeneity of variances and the Shapiro-Wilk test was used to check the normality of residuals of the analysis of variance (ANOVA). A $P$ value less than 0.05 indicated a deviation from homogeneity or normality, 
respectively. Given that most background variables (patient data, perioperative variables) deviated from normality or had nonhomogeneous variances, the Kruskal-Wallis test was used to compare background variables across experimental groups. Where appropriate, a log transform of response variable data was made to ensure the homogeneity of variances or the normality of residuals prior to comparing groups with a 1-way ANOVA. For instance, the variances were heterogeneous for the recovery time to TOF ratio 0.9 among groups (Bartlett $\chi^{2}=129.587, \mathrm{df}=4, P<0.0001$ ), but were homogeneous after a log-transformation $\left(\chi^{2}=3.077, \mathrm{df}=4\right.$, $P=0.545)$. Finally, we compared time to primary and secondary end points for each dose group with a paired $t$ test. All analyses were using statistical software ( $R$ statistical environment, version 2.15.2).

\section{RESULTS}

All enrolled patients were assigned to 1 of the 5 study groups.

One minor protocol violation occurred in the $1 \mathrm{mg} / \mathrm{kg}$ sugammadex group and in the placebo group. One technical failure occurred in the $4 \mathrm{mg} / \mathrm{kg}$ sugammadex group. These 3 patients were excluded from the outcome analysis but were included in the postoperative follow-up to assess residual blockade (Fig. 1). Of the remaining 47 patients included in the outcome analysis, 38 received sugammadex.

Table 1 presents the patient demographics of each of the 5 study groups. Although the low dose sugammadex group $(1 \mathrm{mg} / \mathrm{kg}$ ) consisted of 8 female patients and 1 male patient, the proportion of males/females did not significantly differ between groups $(P=0.1)$. There was no difference in age, body mass index, height, weight, control TOF ratio, control T1 (\%), or ASA physical status score among the 5 study groups $(P>0.1)$.

\section{Recovery Times}

\section{Spontaneous Recovery to Moderate Block}

Table 2 presents the pipecuronium dose and end-tidal sevoflurane concentrations at the time of pipecuronium administration and at the time of pipecuronium reversal. It also presents the time interval from bolus IV administration of pipecuronium to the appearance of 2 TOF twitches, the timepoint of study drug or placebo administration. There was no difference among groups in the total pipecuronium dose, end-tidal sevoflurane concentration at induction, or endtidal sevoflurane concentration at the time of antagonism with sugammadex $(P>0.3)$. There was also no difference among groups in this time interval between pipecuronium administration and the appearance of 2 TOF twitches $(P=0.57)$.

\section{Primary Outcome}

Table 3 presents the primary and secondary end-points (time in minutes to a normalized TOF ratio of 0.9 and time to maximal T1). All patients that received sugammadex, including those in the low sugammadex dose $(1 \mathrm{mg} / \mathrm{kg})$ recovered to normalized TOF ratio of 0.9 in less than 5.0 minutes (95\% lower CI for the lowest dose 70.1\%; for all doses $90.8 \%$ ). Seventy-nine percent of patients in all sugammadex groups reached normalized TOF ratio 0.9 within 2.0 minutes (95\% lower CI for the lowest dose $26.7 \%$; for all doses $63.7 \%$ ).

As presented in Table 3, there was a weak, but statistically significant, difference in the time to TOF ratio 0.9 among the sugammadex-treated groups $(P=0.044)$ because times were shorter in the group receiving $3.0 \mathrm{mg} / \mathrm{kg}$ sugammadex than in the $1.0 \mathrm{mg} / \mathrm{kg}$ sugammadex group $(P=0.0497)$.

In the placebo group, no patient had a satisfactory recovery from the $\mathrm{NMB}$ with a TOF ratio of $0.2 \pm 0.08$

Table 1. Basic Characteristics

\section{Variable}

Sex (males/females)*

Age $(\mathrm{y})$, mean $\pm \mathrm{SD}$ *

BMI $\left(\mathrm{kg} / \mathrm{m}^{2}\right)$, mean $\pm \mathrm{SD} *$

95\% Cl

Median (range)

Height $(\mathrm{m})$, mean $\pm \mathrm{SD}^{*}$

Weight (kg), mean $\pm \mathrm{SD}^{*}$

Control TOF ratio, mean $\pm \mathrm{SD}^{*}$

Control T1 (\%), mean \pm SD*

ASA score I/II/III*
Sug $1 \mathrm{mg} / \mathrm{kg}$

( $n=9)$

$1 / 8$

$49.6 \pm 11.3$

$22.2 \pm 2.28$

20.7-23.8

23 (18-25)

$1.64 \pm 0.07$

$58.7 \pm 8.67$

$1.06 \pm 0.05$

$96.4 \pm 9.72$

$1 / 8 / 0$

$\begin{gathered}\text { Sug } 2 \text { } \mathbf{~ g} / \mathbf{k g} \\ (\mathbf{n}=\mathbf{1 0})\end{gathered}$
$6 / 4$
$52.3 \pm 11.45$
$23.5 \pm 1.9$
$22.3-24.7$
$24.5(20-25)$
$1.73 \pm 0.07$
$72.0 \pm 10.30$
$1.09 \pm 0.07$
$94.6 \pm 6.74$
$1 / 8 / 1$

\begin{tabular}{|c|}
\hline $\begin{array}{l}\text { Sug } 3 \mathrm{mg} / \mathrm{kg} \\
\qquad(\mathrm{n}=10)\end{array}$ \\
\hline $7 / 3$ \\
\hline $52.4 \pm 9.29$ \\
\hline $22.7 \pm 2.45$ \\
\hline $21.2-24.2$ \\
\hline 23.5 (19-25) \\
\hline $1.71 \pm 0.07$ \\
\hline $66.3 \pm 9.19$ \\
\hline $1.08 \pm 0.09$ \\
\hline $98.1 \pm 7.19$ \\
\hline $1 / 8 / 1$ \\
\hline
\end{tabular}

$\begin{array}{cc}\begin{array}{c}\text { Sug } 4 \text { mg/kg } \\ \text { (n = 9) }\end{array} & \begin{array}{c}\text { Placebo } \\ \text { (n = 9) }\end{array} \\ 4 / 5 & 4 / 5\end{array}$

$52.3 \pm 13.50$

$22.3 \pm 2.35$

20.8-23.9

22 (18-25)

$1.67 \pm 0.08$

$63.6 \pm 10.16$

$1.09 \pm 0.06$

$96.0 \pm 7.60$

$2 / 7 / 0$
$46.9 \pm 15.07$

$23.5 \pm 1.61$

22.5-24.6

24 (21-25)

$1.69 \pm 0.16$

$68.4 \pm 14.34$

$1.08 \pm 0.08$

$99.4 \pm 9.80$

$1 / 8 / 0$

$\mathrm{BMI}=$ body mass index; $\mathrm{ASA}=$ American Society of Anesthesiology physical status score; Sug = sugammadex; TOF = train-of-four; $\mathrm{Cl}=$ confidence interval. $* P \geq 0.1$ among the 5 groups.

\section{Table 2. Anesthetic Management and Times to TOFC-2}

\section{Variables}

Pipecuronium total dose (mg/kg)*

Sevoflurane cc. at administration of pipecuronium (vol\%)*

Sevoflurane Et. at antagonism (vol\%)*

Time to TOFC-2 (minutes)*

$\begin{gathered}\text { Sug } 1 \mathbf{~ m g} / \mathbf{k g} \\ (\mathbf{n}=\mathbf{9})\end{gathered}$
$0.07 \pm 0.01$
$1.16 \pm 0.31$
$1.27 \pm 0.41$
$92.5 \pm 31.7$

Sug $2 \mathrm{mg} /$

( $n=10)$

$0.07 \pm 0.01$

$1.05 \pm 0.29$

$1.25 \pm 0.52$

$111 \pm 49.9$

$\begin{gathered}\text { Sug } 3 \mathbf{~ m g} / \mathbf{k g} \\ (\mathbf{n}=10)\end{gathered}$
$0.07 \pm 0.01$
$0.99 \pm 0.17$
$1.12 \pm 0.25$
$120.9 \pm 45.5$

$\begin{gathered}\text { Sug } 4 \mathbf{~ m g} / \mathbf{k g} \\ (\mathbf{n}=\mathbf{9})\end{gathered}$
$0.07 \pm 0.01$
$1.22 \pm 0.39$
$1.37 \pm 0.33$
$91.9 \pm 30.7$

$91.9 \pm 30.7$

$\begin{gathered}\text { Placebo } \\ (\mathbf{n}=\mathbf{9})\end{gathered}$
$0.06 \pm 0.0$
$1.11 \pm 0.27$
$1.37 \pm 0.27$
$113 \pm 57$

Mean \pm SD; Sug = sugammadex; Et. = end-tidal concentration; TOF = train-of-four; TOFC-2 = spontaneous recovery to 2 twitches.

$* P>0.3$ among the 5 groups. 
(mean \pm SD). Thus, each patient $(n=9)$ received rescue medication (neostigmine) after $32.1 \pm 9.9$ minutes (mean \pm SD, range: $19.5-45.8,95 \%$ CI: $24.4-39.6)$. Conventional reversal with neostigmine to a normalized TOF ratio of 0.9 took required $11.6 \pm 5.5$ minutes (mean \pm SD, range: 2.8-20.3, 95\% CI: 7.3-15.9). Given that the aim of the analysis was to compare various doses of sugammadex with saline, reversal times from the placebo group treated with neostigmine were excluded from the analysis of reversal times.

\section{Secondary Outcome}

As presented in Table 3, reversal to final T1 height required significantly more time in all sugammadex groups than reversal of the corresponding TOF ratio $(0.0003<P<0.018)$, but there was no significant difference in reversal times among the four sugammadex groups $(P=0.327)$.

\section{Alternative Outcome}

Reversal times were not different in the sugammadex groups irrespective of whether the end point was normalized 0.9 or nonnormalized TOF ratio $1.0(P=0.24)$.

\section{Postoperative Outcome}

During the first 60 minutes of the postoperative course, the TOF ratio was never less than 0.9 in any of the sugammadex treatment groups. In fact, the average TOF ratio was 1.0 or more throughout this assessment period in all treatment groups (Table 4). No early or late adverse events were observed.

\section{DISCUSSION}

\section{Summary of Results}

We evaluated the efficacy of different doses of sugammadex for the reversal of moderate pipecuronium-induced NMB in surgical patients. To date, this issue has not been investigated. We hypothesized that the doses of sugammadex recommended for the reversal of rocuronium- and vecuronium-induced block would also reverse the effect of pipecuronium.

This study has confirmed our hypothesis, and documented the efficacy and reliability of sugammadex in doses of 1.0 and $2.0 \mathrm{mg} / \mathrm{kg}$ for the antagonism of pipecuroniuminduced block that had spontaneously recovered to 2 twitches

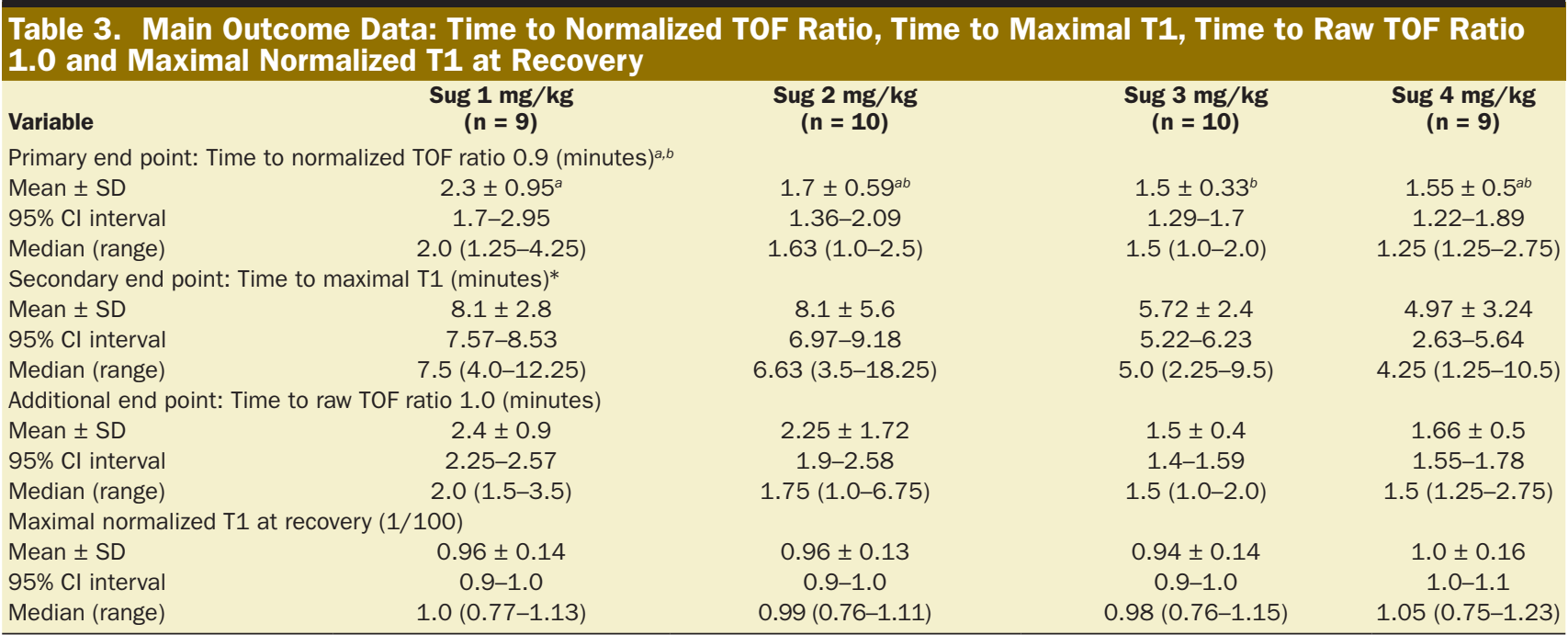

Sug = sugammadex; TOF = train-of-four; $\mathrm{Cl}=$ confidence interval.

aPaired $t$ tests of primary versus secondary end points within dose groups: $1 \mathrm{mg} / \mathrm{kg}: P=0.0004 ; 2 \mathrm{mg} / \mathrm{kg}: P=0.006 ; 3 \mathrm{mg} / \mathrm{kg}: P=0.0003 ; 4 \mathrm{mg} / \mathrm{kg}: P=0.018$. ${ }^{b}$ Groups not sharing lowercase letters are significantly different (Tukey HSD test, $P=0.0497$ ).

\begin{tabular}{|c|c|c|c|c|c|c|}
\hline $\begin{array}{l}\text { Time } \\
\text { (minutes) }\end{array}$ & Statistics & $\begin{array}{l}\text { Sug } 1 \mathrm{mg} / \mathrm{kg} \\
\qquad(\mathrm{n}=9)\end{array}$ & $\begin{array}{l}\text { Sug } 2 \mathrm{mg} / \mathrm{kg} \\
\qquad(\mathrm{n}=10)\end{array}$ & $\begin{array}{l}\text { Sug } 3 \mathrm{mg} / \mathrm{kg} \\
\qquad(\mathrm{n}=10)\end{array}$ & $\begin{array}{l}\text { Sug } 4 \mathrm{mg} / \mathrm{kg} \\
\qquad(\mathrm{n}=9)\end{array}$ & $\begin{array}{c}\text { Placebo } \\
(n=9)\end{array}$ \\
\hline \multirow[t]{3}{*}{0} & Mean $\pm S D$ & $1.1 \pm 0.07$ & $1.03 \pm 0.09$ & $1.1 \pm 0.16$ & $1.08 \pm 0.10$ & $1.0 \pm 0.09$ \\
\hline & $95 \% \mathrm{Cl}$ & $1.06-1.15$ & 0.981 .09 & $1.0-1.2$ & $1.0-1.15$ & $0.95-1.07$ \\
\hline & Median (range) & $1.1(0.97-1.23)$ & $1.02(0.9-1.21)$ & $1.04(1.0-1.41)$ & $1.1(0.91-1.21)$ & $1.0(0.92-1.21)$ \\
\hline \multirow[t]{3}{*}{20} & Mean \pm SD & $1.07 \pm 0.09$ & $1.0 \pm 0.09$ & $1.08 \pm 0.1$ & $1.06 \pm 0.09$ & $1.02 \pm 0.11$ \\
\hline & $95 \% \mathrm{Cl}$ & $1.0-1.13$ & $0.96-1.07$ & $1.0-1.15$ & $1.0-1.13$ & 0.96-1.1 \\
\hline & Median (range) & $1.08(0.9-1.2)$ & $1.02(0.92-1.2)$ & 1.03 (0.98-1.3) & $1.06(0.93-1.2)$ & $1.0(0.93-1.25)$ \\
\hline \multirow[t]{3}{*}{40} & Mean \pm SD & $1.06 \pm 0.01$ & $1.03 \pm 0.08$ & $1.08 \pm 0.13$ & $1.04 \pm 0.11$ & $1.03 \pm 0.09$ \\
\hline & $95 \% \mathrm{Cl}$ & $1.0-1.13$ & 0.99-1.08 & $1.0-1.16$ & $0.97-1.12$ & 0.97-1.09 \\
\hline & Median (range) & $1.05(0.9-1.2)$ & $1.0(0.94-1.2)$ & $1.07(0.92-1.38)$ & $1.02(0.94-1.18)$ & $1.0(0.92-1.23)$ \\
\hline \multirow[t]{3}{*}{60} & Mean \pm SD & $1.08 \pm 0.09$ & $1.02 \pm 0.07$ & $1.08 \pm 0.09$ & $1.07 \pm 0.04$ & $1.04 \pm 0.04$ \\
\hline & $95 \% \mathrm{Cl}$ & $1.02-1.14$ & 0.98-1.06 & $1.03-1.15$ & $1.05-1.11$ & $1.0-1.07$ \\
\hline & Median (range) & $1.07(0.92-1.3)$ & $1.02(0.91-1.1)$ & $1.07(0.99-1.24)$ & $1.06(1.03-1.14)$ & $1.04(0.96-1.1)$ \\
\hline
\end{tabular}

Sug = sugammadex; TOF = train-of-four $; \mathrm{Cl}=$ confidence interval. 
of TOF stimulation. In fact, $79 \%$ of patients who were given sugammadex fulfilled the primary outcome within $2.0 \mathrm{~min}-$ utes, and the remaining $21 \%$ reached a normalized TOF ratio 0.9 within 5.0 minutes. From a practical point of view, recovery of the TOF ratio to $\geq 0.9$ in less than 5 minutes is perfectly adequate and, since it can be achieved using 1.0 or $2.0 \mathrm{mg} / \mathrm{kg}$ of sugammadex, the administration of larger doses (like 3.0 and $4.0 \mathrm{mg} / \mathrm{kg}$ ) is not indicated in this situation.

Recovery of T1 to maximum height took 5 to 8 minutes, longer than recovery of TOF ratio to 0.9 , and exhibited a similar trend of dose-effect relationship to the primary outcome measures (Table 3). Although the delay of T1 recovery behind the TOF ratio of 0.9 or 1.0 did not ensure full recovery from the block in this setting, ${ }^{22}$ there does not appear to be any clinical implications of this finding. Indeed, RPONB, recurrent $\mathrm{NMB}$, or critical adverse events did not occur during the postoperative period (Table 4).

We chose to reverse a moderate (TOFC-2) pipecuronium-induced block to be consistent with most investigations exploring the reversal of other neuromuscular blocking agents with sugammadex. ${ }^{16,23,24}$ We selected the doses of sugammadex based on prior work that reported doses of $2.0 \mathrm{mg} / \mathrm{kg}$ as standard for reversal of moderate rocuronium and vecuronium-induced block, ${ }^{16,24}$ $1.0 \mathrm{mg} / \mathrm{kg}$ as low dose for reversal of rocuronium, ${ }^{13}$ $3.0 \mathrm{mg} / \mathrm{kg}$ as intermediate dose, and $4.0 \mathrm{mg} / \mathrm{kg}$ as high dose. In the absence of data about the effect of low dose sugammadex on pipecuronium block, we assumed that insufficient reversal may occur and therefore we chose a placebo comparator to distinguish the effect of sugammadex from spontaneous recovery. With regard to the potential of prolonged effect from pipecuronium, we prepared for rescue treatment with neostigmine if recovery was incomplete after 45 minutes. This time limit was agreed upon with the operating room team. In fact, rescue treatment was employed only in the placebo group approximately 30 minutes after saline administration and a stagnated TOF ratio of around 0.20 for at least 5 minutes. A TOF ratio of 0.20 represents a TOFC -4 with significant and palpable fade. Despite this considerable degree of spontaneous recovery, neostigmine-induced antagonism was slow (on average 11-12 minutes). That said, if the TOFC is 4 and rapid reversal is unnecessary, administration of neostigmine has distinct economic benefits.

Although most relevant publications about sugammadex described uncorrected (nonnormalized) acceleromyographic TOF ratio 0.9 as reversal end point, ${ }^{16,23,24}$ actually normalized TOF ratio 0.9 is recommended to exclude residual NMB.$^{25}$ It is even suggested that the acceleromyographic TOF ratio should be 1.0 or greater to exclude clinically relevant paralysis. ${ }^{13,26}$ In this study, reversal times after sugammadex were similar whether normalized TOF ratio 0.9 or nonnormalized TOF ratio 1.0 was the end point (Table 3). This is in agreement with the results of Capron et al. ${ }^{26}$ who demonstrated that the negative predictive values of acceleromyographic TOF ratio of 1.0 and normalized TOF ratio of 0.9 are similar to detect residual paralysis and superior to nonnormalized TOF ratio 0.9 . Normalization, that is, dividing the final TOF recovery value noted at the acceleromyographic monitor screen by the control value taken before the injection of neuromuscular blocking agent, is a complex procedure, and therefore direct measurement of TOF 1.0 displayed on the monitor screen may offer advantages for clinical practice by its relative simplicity.

As the TOF ratio reflects the effects of NMBAs at the presynaptic site of the neuromuscular junction, the T1 response reflects the events at the postjunctional endplate and exhibits the muscle force generated. ${ }^{27}$ Accordingly, not only the TOF ratio but also the amplitude of the contraction (T1 twitch height) should exceed $90 \%$ of control for neuromuscular recovery to be considered acceptable. ${ }^{28}$ Classically, during spontaneous recovery or after anticholinesterases, the T1 recovered first followed by the TOF ratio soon after then the block ended. ${ }^{28}$ However, like others, ${ }^{22,29}$ we observed reduced T1 twitches in a few minutes after sugammadex while TOF ratio 1.0 was reached. The delay of $\mathrm{T} 1$ twitch behind the TOF ratio recovery is not unique to pipecuronium and occurred also when rocuronium was antagonized with sugammadex. ${ }^{22,29}$

Residual paralysis may occur in the postoperative period even after successful reversal of the block at the end of anesthesia and surgery. ${ }^{30-32}$ Therefore, we monitored all patients during the early postoperative period using acceleromyographic measurements and clinical tests. We did not observe PORNB in our postanesthesia care unit.

In the present investigation, sevoflurane anesthesia was maintained until recovery of the TOF ratio to 1.0. Several studies have noted that antagonism of residual NMB with anticholinesterases was prolonged by anesthetizing concentrations of volatile anesthetics. ${ }^{14,33}$ The enhancement of pipecuronium block by volatile drugs has been published as well. ${ }^{9,10,34}$ However, when sugammadex was administered, the reversal was satisfactory under sevoflurane anesthesia, thus supporting those findings that sevoflurane has little influence on the efficacy of sugammadex. ${ }^{13,24}$ Indeed, in our patients, 1.0 and $2.0 \mathrm{mg} / \mathrm{kg}$ of sugammadex produced average reversal times of 2.3 and 1.7 minutes, respectively. Similar times ( 3.3 and 1.7 minutes, respectively) were measured by others when a moderate rocuronium-induced block was reversed with sugammadex during propofol anesthesia. ${ }^{23,24}$

There may be both chemical and pharmacological reasons to explain the efficiency of sugammadex for the reversal of pipecuronium. First, the value of affinity constant $(\mathrm{Ka})$ for pipecuronium $\left(161 \pm 28 \times 10^{6} \mathrm{M}^{-1}\right)$ is about 10 or 18 times greater than for rocuronium or vecuronium, respectively, and 60 times greater than the $K a$ for pancuronium. ${ }^{b}$ The affinity constant (also known as the association constant) is a numerical measure of the bonding affinity of 2 molecules at equilibrium. In other words, this constant describes the molecular binding strengths between the NMBA and sugammadex. Since the $K a$ for sugammadex-pancuronium is 60 times less than for sugammadex-pipecuronium, the present observations cannot be extrapolated to sugammadex reversal of pancuronium. Second, pipecuronium is 6 to 7 times more potent than rocuronium, ${ }^{9,17}$ and its molecular weight is also $30 \%$ greater than the molecular weight of rocuronium, thus fewer pipecuronium than rocuronium molecules are required to induce an equivalent level of

${ }^{b}$ Available at: www.pmda.go.jp/english/service/pdf/drugs/bridion_jan2010_e. pdf (Page 15, paragraph 3.(i).A.(1).1). 
NMB. Since the binding of the relaxant by sugammadex is a one-to-one molecular interaction, the encapsulation of almost all of the pipecuronium molecules requires relatively small amounts of sugammadex.

Following the introduction of atracurium and vecuronium in the mid-1980s, the clinical use of traditional, long acting drugs such as pancuronium has dramatically declined. This transpired because of the recognition that long-acting drugs were associated with a higher incidence of $\mathrm{RPONB}^{35}$ and the resultant potential for adverse clinical consequences. ${ }^{36}$ It is now apparent, however, that residual paresis following the administration of intermediate-acting drugs is still common. ${ }^{37-39}$ The duration of effect of these drugs is longer than most clinicians realize, ${ }^{31}$ and reversal of residual block with anticholinesterase inhibitors is often slow and incomplete. ${ }^{15}$

The routine pharmacologic reversal of blocks from all intermediate-acting muscle relaxants has been suggested and objective monitoring strongly advised. ${ }^{40}$ Repetitive bolus or infusion administration of intermediate-acting relaxants for surgery of long duration endorsed the occurrence of RPONB. ${ }^{41}$ Therefore, one must carefully consider not only the expected duration of action of a muscle relaxant but also the facility of its reversal and its possible side effects (histamine release, tachycardia, hypertension, hypotension, allergy, or active metabolites). For those clinicians who have access to sugammadex and pipecuronium the "requirement" for using short- or intermediate-acting NMBAs for brief procedures is no longer absolute. These data can be used to argue that pipecuronium can safely be administered for any procedure if one can anticipate spontaneous recovery to a TOFC-2. Thus, a single $200 \mathrm{mg}$ vial sugammadex might be adequate for even the morbidly obese, provided that the TOFC has returned to a value of 2 .

\section{Limitations}

This study has not investigated the efficacy of sugammadex in reversing profound, deep and shallow pipecuronium block. Antagonism after repetitive pipecuronium administration during surgery of extreme long duration (6-8 hours) was not studied either. Further investigation is needed to establish the full profile of antagonism of pipecuroniuminduced NMB with sugammadex. Although the antagonism of pipecuronium was perfectly adequate in all 9 patients who received $1.0 \mathrm{mg} / \mathrm{kg}$ of sugammadex, data from a larger sample size would be highly desirable before this dose can be recommended with confidence for pipecuronium reversal at TOFC-2.

In conclusion, we provide evidence on the adequacy of reversal of moderate pipecuronium-induced NMB with sugammadex under sevoflurane maintenance anesthesia. We demonstrate that once the TOFC has spontaneously returned to 2 responses following pipecuronium administration, it is unnecessary to administer sugammadex in a dose larger than $2.0 \mathrm{mg} / \mathrm{kg}$ in order to achieve satisfactory neuromuscular recovery, and even this may be more than sufficient. Our conclusions mandate that the clinician needs to monitor neuromuscular function. A conventional (qualitative) peripheral nerve stimulator is sufficient for the detection of a TOFC-2 degree of NMB.

\section{DISCLOSURES}

Name: Edömér Tassonyi, MD, PhD, DSc.

Contribution: This author helped design the study, analyze the data, and write the manuscript.

Attestation: Edomer Tassonyi has seen the original study data, reviewed the analysis of the data, approved the final manuscript, and is the author responsible for archiving the study files.

Name: Adrienn Pongrácz, MD.

Contribution: This author helped conduct the study and write the manuscript.

Attestation: Adrienn Pongrácz has seen the original study data, reviewed the analysis of the data, approved the final manuscript, and is the author responsible for archiving the study files.

Name: Réka Nemes, MD.

Contribution: This author helped conduct the study and write the manuscript.

Attestation: Réka Nemes has seen the original study data, reviewed the analysis of the data, approved the final manuscript, and is the author responsible for archiving the study files.

Name: László Asztalos, MD.

Contribution: This author helped conduct the study and write the manuscript.

Attestation: László Asztalos has seen the original study data, reviewed the analysis of the data, approved the final manuscript, and is the author responsible for archiving the study files. Name: Szabolcs Lengyel, PhD, DSc.

Contribution: This author helped analyze the data.

Attestation: Szabolcs Lengyel has seen the original study data, reviewed the analysis of the data, approved the final manuscript, and is the author responsible for archiving the study files.

Name: Béla Fülesdi, MD, PhD, Dsc.

Contribution: This author helped design the study, analyze the data, and write the manuscript.

Attestation: Béla Fülesdi has seen the original study data, reviewed the analysis of the data, approved the final manuscript, and is the author responsible for archiving the study files.

This manuscript was handled by: Ken B. Johnson, MD.

\section{REFERENCES}

1. Tuba Z. Synthesis of 2 beta,16 beta-bis-(4'-dimethyl-1'-piperazino)-3 alpha, 17 beta-diacetoxy- 5 alpha-androstane dibromide and related compounds. Arzneimittelforschung 1980;30:342-6

2. Baird WL, Reid AM. The neuromuscular blocking properties of a new steroid compound, pancuronium bromide. A pilot study in man. Br J Anaesth 1967;39:775-80

3. Boros M, Szenohradszky J, Marosi G, Tóth I. Comparative clinical study of pipecurium bromide and pancuronium bromide. Arzneimittelforschung 1980;30:389-93

4. Tassonyi E, Neidhart P, Pittet JF, Morel DR, Gemperle M. Cardiovascular effects of pipecuronium and pancuronium in patients undergoing coronary artery bypass grafting. Anesthesiology 1988;69:793-6

5. Futo J, Kupferberg JP, Moss J. Inhibition of histamine $\mathrm{N}$-methyltransferase (HNMT) in vitro by neuromuscular relaxants. Biochem Pharmacol 1990;39:415-20

6. Azad SS, Larijani GE, Goldberg ME, Beach CA, Marr AT, Seltzer JL. A dose-response evaluation of pipecuronium bromide in elderly patients under balanced anesthesia. J Clin Pharmacol 1989;29:657-9

7. Pittet JF, Tassonyi E, Morel DR, Gemperle G, Richter M, Rouge JC. Pipecuronium-induced neuromuscular blockade during nitrous oxide-fentanyl, isoflurane, and halothane anesthesia in adults and children. Anesthesiology 1989;71:210-3

8. Larijani GE, Bartkowski RR, Azad SS, Seltzer JL, Weinberger MJ, Beach CA, Goldberg ME. Clinical pharmacology of pipecuronium bromide. Anesth Analg 1989;68:734-9

9. Foldes FF, Nagashima H, Nguyen HD, Duncalf D, Goldiner PL. Neuromuscular and cardiovascular effects of pipecuronium. Can J Anaesth 1990;37:549-55 
10. Wierda JM, Richardson FJ, Agoston S. Dose-response relation and time course of action of pipecuronium bromide in humans anesthetized with nitrous oxide and isoflurane, halothane, or droperidol and fentanyl. Anesth Analg 1989;68:208-13

11. Pittet JF, Tassonyi E, Schopfer C, Morel DR, Leemann P, Mentha G, Le Coultre C, Steinig DA, Benakis A. Dose requirements and plasma concentrations of pipecuronium during bilateral renal exclusion and orthotopic liver transplantation in pigs. $\mathrm{Br}$ J Anaesth 1990;65:779-85

12. Srivastava A, Hunter JM. Reversal of neuromuscular block. Br J Anaesth 2009;103:115-29

13. Pongrácz A, Szatmári S, Nemes R, Fülesdi B, Tassonyi E. Reversal of neuromuscular blockade with sugammadex at the reappearance of four twitches to train-of-four stimulation. Anesthesiology 2013;119:36-42

14. Kirkegaard H, Heier T, Caldwell JE. Efficacy of tactile-guided reversal from cisatracurium-induced neuromuscular block. Anesthesiology 2002;96:45-50

15. Bom A, Bradley M, Cameron K, Clark JK, Van Egmond J, Feilden H, MacLean EJ, Muir AW, Palin R, Rees DC, Zhang MQ. A novel concept of reversing neuromuscular block: chemical encapsulation of rocuronium bromide by a cyclodextrin-based synthetic host. Angew Chem Int Ed Engl 2002;41:266-70

16. Suy K, Morias K, Cammu G, Hans P, van Duijnhoven WG, Heeringa M, Demeyer I. Effective reversal of moderate rocuronium- or vecuronium-induced neuromuscular block with sugammadex, a selective relaxant binding agent. Anesthesiology 2007;106:283-8

17. Lowry DW, Mirakhur RK, McCarthy GJ, Carroll MT, McCourt KC. Neuromuscular effects of rocuronium during sevoflurane, isoflurane, and intravenous anesthesia. Anesth Analg 1998;87:936-40

18. Claudius C, Skovgaard LT, Viby-Mogensen J. Is the performance of acceleromyography improved with preload and normalization? A comparison with mechanomyography. Anesthesiology 2009;110:1261-70

19. Ali HH. Criteria of adequate clinical recovery from neuromuscular block. Anesthesiology 2003;98:1278-80

20. Stanley JC, Mirakhur RK, Bell PF, Sharpe TD, Clarke RS. Neuromuscular effects of pipecuronium bromide. Eur J Anaesthesiol 1991;8:151-6

21. Schulz KF, Grimes DA. Generation of allocation sequences in randomised trials: chance, not choice. Lancet 2002;359:515-9

22. Suzuki T. A train-of-four ratio of 0.9 may not certify adequate recovery after sugammadex. Acta Anaesthesiol Scand 2011;55:368-9

23. Gijsenbergh F, Ramael S, Houwing N, van Iersel T. First human exposure of Org 25969, a novel agent to reverse the action of rocuronium bromide. Anesthesiology 2005;103:695-703

24. Pühringer FK, Gordon M, Demeyer I, Sparr HJ, Ingimarsson J, Klarin B, van Duijnhoven W, Heeringa M. Sugammadex rapidly reverses moderate rocuronium- or vecuronium-induced neuromuscular block during sevoflurane anaesthesia: a doseresponse relationship. Br J Anaesth 2010;105:610-9

25. Fuchs-Buder T, Claudius C, Skovgaard LT, Eriksson LI, Mirakhur RK, Viby-Mogensen J; 8th International Neuromuscular Meeting. Good clinical research practice in pharmacodynamic studies of neuromuscular blocking agents II: the Stockholm revision. Acta Anaesthesiol Scand 2007;51:789-808

26. Capron F, Alla F, Hottier C, Meistelman C, Fuchs-Buder T. Can acceleromyography detect low levels of residual paralysis? A probability approach to detect a mechanomyographic train-offour ratio of 0.9. Anesthesiology 2004;100:1119-24
27. Jonsson M, Gurley D, Dabrowski M, Larsson O, Johnson EC, Eriksson LI. Distinct pharmacologic properties of neuromuscular blocking agents on human neuronal nicotinic acetylcholine receptors: a possible explanation for the train-of-four fade. Anesthesiology 2006;105:521-33

28. Kopman AF, Klewicka MM, Neuman GG. The relationship between acceleromyographic train-of-four fade and single twitch depression. Anesthesiology 2002;96:583-7

29. Staals LM, Driessen JJ, Van Egmond J, De Boer HD, Klimek M, Flockton EA, Snoeck MM. Train-of-four ratio recovery often precedes twitch recovery when neuromuscular block is reversed by sugammadex. Acta Anaesthesiol Scand 2011;55:700-7

30. Cedborg AI, Sundman E, Bodén K, Hedström HW, Kuylenstierna R, Ekberg O, Eriksson LI. Pharyngeal function and breathing pattern during partial neuromuscular block in the elderly: effects on airway protection. Anesthesiology 2014;120:312-25

31. Debaene B, Plaud B, Dilly MP, Donati F. Residual paralysis in the PACU after a single intubating dose of nondepolarizing muscle relaxant with an intermediate duration of action. Anesthesiology 2003;98:1042-8

32. Murphy GS, Szokol JW, Avram MJ, Greenberg SB, Shear T, Vender JS, Gray J, Landry E. Postoperative residual neuromuscular blockade is associated with impaired clinical recovery. Anesth Analg 2013;117:133-41

33. Morita T, Tsukagoshi $H$, Sugaya T, Saito $S$, Sato H, Fujita T. Inadequate antagonism of vecuronium-induced neuromuscular block by neostigmine during sevoflurane or isoflurane anesthesia. Anesth Analg 1995;80:1175-80

34. Nakao Y, Ohno M, Imai M, Kemmotsu O. Neuromuscular effects of pipecuronium during sevoflurane anesthesia compared with isoflurane and enflurane anesthesia. J Anesth 1993;7:405-10

35. Bevan DR, Smith CE, Donati F. Postoperative neuromuscular blockade: a comparison between atracurium, vecuronium, and pancuronium. Anesthesiology 1988;69:272-6

36. Berg H, Roed J, Viby-Mogensen J, Mortensen CR, Engbaek J, Skovgaard LT, Krintel JJ. Residual neuromuscular block is a risk factor for postoperative pulmonary complications. A prospective, randomised, and blinded study of postoperative pulmonary complications after atracurium, vecuronium and pancuronium. Acta Anaesthesiol Scand 1997;41:1095-103

37. Grosse-Sundrup M, Henneman JP, Sandberg WS, Bateman BT, Uribe JV, Nguyen NT, Ehrenfeld JM, Martinez EA, Kurth $\mathrm{T}$, Eikermann M. Intermediate acting non-depolarizing neuromuscular blocking agents and risk of postoperative respiratory complications: prospective propensity score matched cohort study. BMJ 2012;345:e6329

38. Kim KS, Lew SH, Cho HY, Cheong MA. Residual paralysis induced by either vecuronium or rocuronium after reversal with pyridostigmine. Anesth Analg 2002;95:1656-60

39. Esteves S, Martins M, Barros F, Barros F, Canas M, Vitor P, Seabra M, Castro MM, Bastardo I. Incidence of postoperative residual neuromuscular blockade in the postanaesthesia care unit: an observational multicentre study in Portugal. Eur J Anaesthesiol 2013;30:243-9

40. Eriksson LI. Evidence-based practice and neuromuscular monitoring: it's time for routine quantitative assessment. Anesthesiology 2003;98:1037-9

41. Plaud B, Debaene B, Donati F, Marty J. Residual paralysis after emergence from anesthesia. Anesthesiology 2010;112:1013-22 